\title{
A study of pedagogical leadership plans in early childhood education settings in Finland
}

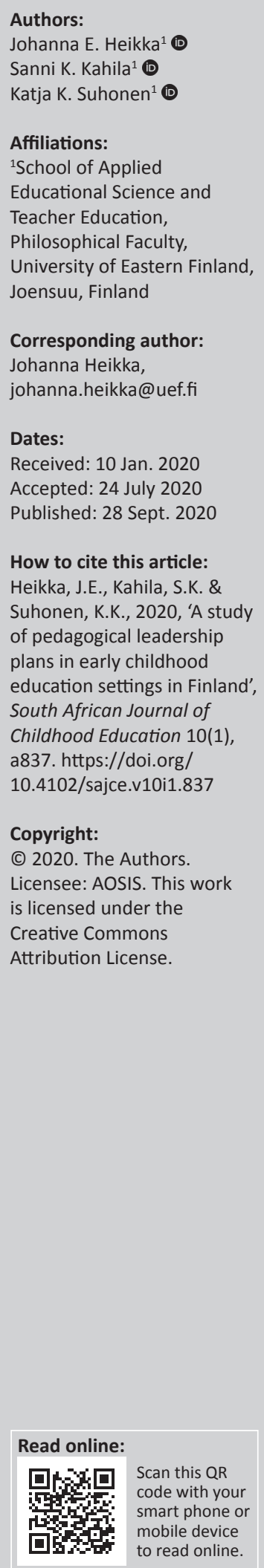

Background: Current research on early childhood education (ECE) leadership as well as on policy reform in Finland suggests that pedagogical leadership must be considered as a purposeful and planned process. Pedagogical leadership plans play a key role in the purposeful and effective enactment of pedagogical leadership in ECE settings.

Aim: This study aimed at examining the contents of pedagogical leadership plans drawn up in Finnish ECE centres to interpret the perceptions of the centre directors on the implementation of pedagogical leadership in their settings.

Setting: This study examines pedagogical leadership plans in ECE settings in Finland.

Methods: We used inductive content analysis to examine documents drawn up by nine ECE centre directors as pedagogical leadership plans for their centres. Our analysis identified four main categories that describe how the ECE centre directors conceive the enactment of pedagogical leadership.

Results: The findings revealed that the focus of the plans was on leading pedagogical issues and processes within the ECE centres. Creating structures for pedagogical development and reflection were emphasised in the plans. The plans reflected a distributed leadership approach.

Conclusion: The findings of the study provide information about how the ECE directors intend to enact pedagogical leadership and assist ECE leaders to develop leadership planning in their work settings. In this way, the study contributes to leadership development within the ECE sector.

Keywords: early childhood education; leadership; pedagogical leadership; leadership plans.

\section{Introduction}

The significance of this study is based on current research on early childhood education (ECE) leadership as well as on policy reform in ECE in Finland, which suggest that pedagogical leadership must be considered as a purposeful and planned process. The Finnish Education Evaluation Centre (FINEEC 2018) launched quality criteria for ECE according to which leadership of ECE should be planned and goal-oriented. The municipalities in Finland are free to decide the planning procedures, as a result of which planning practices and the forms and contents of the plans vary.

In Finland, ECE services are mainly provided by municipalities. The enactment of pedagogical leadership by diverse ECE stakeholders is challenged by a complex organisational structure, and thus the written plans, as artifacts (Spillane 2006), are needed to guide leadership practice. Early childhood education centre directors usually lead a cluster of units and are removed from the daily practices of their staff. In ECE organisations, ECE leadership is distributed between diverse stakeholders, including the directors of the centres and ECE teachers working at ECE centres, in addition to municipal-level ECE leadership and government steering and policies. Teachers' engagement in pedagogical leadership is essential because the implementation of national curriculum reforms requires the commitment of teachers as developers of ECE pedagogy in their child groups aligned with the plans made with the centre directors (Act on Early Childhood Education and Care 540/2018; EDUFI 2018).

In such contexts, a leadership approach and tools that create interdependence between ECE centre directors and teachers through shared construction and enactment of visions and strategies is even more crucial. The ECE centre directors are responsible for developing a common operational 
culture in their centres. This involves pedagogical leadership, the development of ECE and assessment systems as well as educators' professional competence and working conditions (EDUFI 2018).

The Act on Early Childhood Education and Care (540/2018) and the National Core Curriculum for Early Childhood Education and Care (EDUFI 2018) made ECE teachers responsible for pedagogy on their staff teams, which usually include one or two childcare nurses. Under new legislation, a team can comprise the teacher together with a social educator specialising in ECE and an additional staff member, such as a childcare nurse. The pedagogical responsibility of teachers includes the planning, development and assessment of teaching in their child groups (EDUFI 2018). In Finland, the groups of children are formed appropriately by age, sibling relationships or need for support. In child groups under 3 years of age, the ratio is four children per one qualified educator. In groups with full-time children over the age of three, the ratio is $7: 1$, and in groups with part-time children, it is 13:1. The number of children in a group may not exceed that requiring more than three eligible educators (Act 540/2018). Early childhood education teachers hold a 3-year Bachelor of Education degree from a university. Childcare nurses have a vocational qualification in social welfare or healthcare.

According to Spillane et al. (2004) and Spillane (2006), leadership artifacts are essential tools for directing leadership, especially when leadership is distributed between different people and throughout organisational contexts. The plans as drafted by ECE centre directors reflect the emphases and understandings of the directors with regard to the enactment of pedagogical leadership and therefore enable interpretation as to how these plans support, are aligned with and direct the enactment of pedagogical leadership in ECE centres.

\section{Pedagogical leadership in early childhood education contexts}

The concept of pedagogical leadership is at an early stage of development in ECE. Current conceptualisations are based on understanding early childhood pedagogy as a holistic phenomenon, integrating education and care, and the community aspects of leadership. Heikka and Waniganayake (2011) considered that the term is connected not only with children's learning, but also with the capacity building of an early childhood professional, and the values and beliefs about education held by the wider society or community. In early childhood settings, pedagogical leadership means taking responsibility for the shared understanding of the aims and methods of the learning and teaching of young children from birth to 8 years of age. Similarly, O'Sullivan (2009) defined pedagogical leadership as a leader's understanding of pedagogy and learning. Leaders enable pedagogy and learning by taking into account the different facets of service and the relationships within the wider community. Furthermore, Parrila and Fonsén (2016) stated that pedagogical leadership of ECE has the main goal of guaranteeing a child's good growth, well-being and learning. These broad understandings of pedagogical leadership differ from, for example, O'Gorman and Hard's (2013) understanding that pedagogical leadership focuses mainly on the activities of leading, developing and implementing early education curricula.

The concept of pedagogical leadership is sometimes used in a general way to refer to responsibilities that are not considered management tasks (Karila 2001). However, for example Finnish ECE centre directors are usually expected to assume both managerial and pedagogical leadership responsibilities, and therefore any analysis that attempts to separate these sometimes overlapping responsibilities is problematical (Heikka \& Waniganayake 2011). For example, Nivala (1999) and Fonsén (2008) considered that pedagogical leadership includes the responsibilities that are traditionally seen as the management and administration aspects of leading if the aim of these functions is to improve pedagogical practice.

Different understandings of the concept reflect different perceptions of leadership and of the professionals who are seen to enact pedagogical leadership in ECE organisations. In a narrower sense, a pedagogical leader can be understood as a person who is a manager of a pedagogical organisation such as a school (Soukainen 2013). These are typically people who hold managerial positions at the upper levels of the organisations and who are seen to have the responsibility for setting education goals. This understanding of leadership responsibilities based on a hierarchical system is often connected with the leader-follower understanding of leadership (Ebbeck \& Waniganayake 2004:24). This reinforces conventional leadership thinking about the roles of leaders as creators of a vision and of teachers as being the followers, responsible for implementing the vision. For example, according to Atkinson and Biegun (2017:61), pedagogical leadership is often considered to belong to those who work in governmental spheres and establish what is 'best practice'. The term is often associated with an image of a specialist 'who will dictate indicators of quality, suggesting certainty and fixed ways of practicing'. This is contradictory to the caring nature of educators, and so they may be unwilling to take the role of a leader (Atkinson \& Biegun 2017:61).

The confusion between the leader position and the concept itself can be based on the fact that in Finland, for instance, pedagogical leadership is seen as a focal responsibility in the work of ECE centre directors (Heikka 2014). This differs from definitions in which the term 'pedagogical leader' reflects the role of a designated educator who is responsible for advancing pedagogical leadership in their own child group, as in Norway, or in the whole ECE centre, as in Australia (Engel, Barnett, Anders \& Tagum 2015:62; Rouse \& Spradbury 2016). Atkinson and Biegun (2017) considered how pedagogical leadership could be enacted and described so 
that it could resist hierarchical composition in cases where there are leaders and followers. When leadership is enacted by questioning daily practices, leadership can become a part of the work of educators. Instead of defining pedagogical leadership through the leader position, Parrila and Fonsén (2016:24) described it as an 'umbrella concept' that comprises concrete leading, such as pedagogical leading and leading of pedagogy: any person who enacts these functions is a pedagogical leader.

New findings indicate that the teachers' role as leaders of pedagogy in their staff teams, which usually include one university-qualified ECE teacher and two childcare nurses, is expected among ECE professionals (Heikka, Halttunen \& Waniganayake 2018). However, success in teacher leadership demands well-planned and structured strategies of distributed pedagogical leadership in ECE centres (Heikka et al. 2019). In addition, competences required from the leader include both knowledge of ECE and broader leadership skills (Muijs et al. 2004).

In classical writings about pedagogical leadership, Sergiovanni (1996) considered pedagogical leadership to be teachers' pedagogical work with children, positing that principals facilitate this process by means of pedagogy (Sergiovanni 1996). According to Male and Palaiologou (2015), when the term 'pedagogy' occurs in conjunction with the concept of leadership, it is ambiguous and needs further explanation. They argued that the interpretation that pedagogical leadership means only supporting learning and teaching is too narrow in the 21st-century context. They considered that pedagogical leadership is connected with the idea of teachers being leaders in their learning environment, but they used the term more as a praxis that goes beyond that way of conceptualisation. Pedagogical leadership includes the development of ecological interactions in the community, knowledge constructed by using accessible resources, for instance technology, and activities with every participant (Male \& Palaiologou 2015).

According to Heikka (2014), the need to develop skills in leading organisational change in early childhood settings has increased interest in distributed pedagogical leadership. Within the framework of distributed pedagogical leadership, pedagogical development is understood as a responsibility that is enacted by all leadership stakeholders holding formal and informal leadership positions at different levels of ECE organisation (Halttunen 2009; Heikka 2014). According to Heikka (2014), the enactment of distributed pedagogical leadership includes firstly the enhancement of a shared consciousness of visions and strategies between the ECE stakeholders. It also means the distribution of responsibilities for pedagogical leadership as well as distributing the enactment of pedagogical improvement within ECE centres, which can be promoted by focusing on the roles and responsibilities of the ECE teachers within pedagogical team processes. The authority is shared as the teachers work independently but interdependently as pedagogical developers in their own child groups. Distributing and clarifying power relationships between the stakeholders includes enhancing ECE centre directors' and teachers' participation in decision-making about developmental proceedings in municipalities (Heikka, Waniganayake \& Hujala 2013). The implementation of distributed pedagogical leadership includes also developing a strategy with which leaders ensure that the enactment of distributed leadership is well planned, goal-oriented and regularly assessed and developed (Heikka et al. 2013). The strategy for distributed pedagogical leadership makes leadership procedures and responsibilities explicit for professionals.

Pedagogical leadership is not just leading practice, but rather a way of enhancing critical reflection that aims to concretise pedagogical thinking in the practices of early childhood education. In this way, pedagogical leadership also includes the development of a staff who is able to direct his or her own pedagogical work (Corrick \& Reed 2019). A pedagogical leader has the responsibility to support and develop educators to reflect and research, and furthermore to inspire and shape a learning organisation (O'Sullivan 2009). Similarly, Stremmel (2019) emphasised pedagogical leadership as developing reflective teachers in early childhood settings.

A pedagogical leader challenges herself or himself and staff constantly to reflect on their work from the perspective of the learning and well-being of a child, and promotes mutual learning and development of integrity (Fonsén \& Parrila 2016). Pedagogical leaders can do this in several ways, for example, by participating in and influencing the curriculum decisions and discussion of the team as well as by organising meetings with the teachers. The qualified teachers lead the staff teams and curriculum work in their teams (Waniganayake et al. 2017). Kagan and Hallmark (2001) stated that a pedagogical leader attempts to create a bridge between research and practice by using theory-based knowledge and leaders' own experiences. Pedagogical leaders bring new information to other educators and parents, but they also reflect early care and education practices to enable them to provide the best for children.

Heikka (2014) considered interdependence as a key concept of distributed pedagogical leadership. This means that leaders and teachers have their own responsibilities in pedagogical leadership, but that these areas should be planned and aligned to achieve common goals in early childhood settings. Effective implementation of the core curriculum of ECE and the creation of the structures for pedagogical development means clarification of the responsibilities and tasks of the ECE centre directors and the teachers as well as crystallising the goals and processes of the development work (Fonsén 2014; Heikka 2014). However, the idea of planning pedagogical leadership has not gained much attention among researchers, and therefore little is known about the practices or skills of ECE centre directors in enacting planned and goal-oriented pedagogical development in their centres. A recently 
published pioneering paper indicates that pedagogical leadership plans were perceived to have positive impacts on the way leadership was enacted between ECE centre directors and teachers. The plans of pedagogical leadership were also perceived to increase positive experiences towards directors among staff as it clarified the roles and the responsibilities of the staff members and made the processes in pedagogical development visible for everyone. In this way, the plans supported organised and well-managed pedagogical development in the centre. The plans also seemed to create interdependencies between pedagogical leadership enactment by teachers and directors in early childhood settings (Heikka \& Suhonen 2019).

Based on this review, one can conclude that pedagogical leadership plans play a key role in the purposeful and effective enactment of pedagogical leadership in ECE settings. Therefore, this study aims at examining the contents of pedagogical leadership plans drawn up in Finnish ECE settings to interpret the perceptions of the centre directors on the implementation of pedagogical leadership in their settings. Informed by the review for the basis of analysis, the research task was refined into the following research question: How is the enactment of pedagogical leadership conceived by ECE centre directors in accordance with the statements included in pedagogical leadership plans?

\section{Methodology Study design}

The data consist of nine written documents of pedagogical leadership plans drawn up by ECE centre directors in Finland who were leaders of 10 different ECE centres in a mid-sized town in Finland during 2016 and 2017. The plans differed in structure, length and content. Some of the plans were rich descriptions of the aims, tasks, means and structures of leadership, whereas others were more like annual calendars, describing the monthly tasks of the staff. The plans were drawn up as a part of the development project 'Developing, evaluating and changing the operational culture of ECE', run by the municipality together with university consultants. Plans were generated by the centre directors who were responsible for ECE centres in the municipality. The aim of the plans was to develop ECE leadership and pedagogy in the municipality. In Finland, leadership activities must be planned to ensure the quality of ECE (FINEEC 2018). Therefore, the plans for pedagogical leadership were generated in the project. Early childhood education centre directors were instructed to develop planned and goaloriented pedagogical leadership in their ECE centres, but were given no detailed instructions about what the actual plans should contain. The idea for the plans came from the leaders of the municipality, and the project afforded a platform for the development work. The process was guided by the leaders of the municipality, and the university consultants did not provide any detailed assistance for the authorship or contents of the plans.

\section{Analysis of the study}

Analysis of the documents was conducted using the inductive qualitative content analysis method (Patton 2015; Miles, Huberman \& Saldaña 2014). The analysis sought to systematically create a description of the phenomenon of pedagogical leadership as reflected in the pedagogical leadership plans by organising information concisely and clearly without omitting any relevant information (see Tuomi \& Sarajärvi 2018:123). The analysis sought to identify the core elements of pedagogical leadership by forming categories through certain phases and to generate new explanations through the findings emerging from the data (see Patton 2015).

The inductive content analysis of this study was begun by reading through all the documents to find out what the data offered for the study. Each document was scrutinised separately, and thoughts about the emerging views of pedagogical leadership were written down. The analysis process was planned and started by creating an understanding of the information contained in the data. In the first phase of the analysis, all information focusing on the research question was separated and coded, one document at a time, before collecting the codes emerging from each document into one file. In the second phase, the analysis was continued by grouping the codes according to their similarities and differences. In the third phase, the groups of codes were combined as far as possible to formulate the main categories. The result was the formulation of four main categories: setting the goals and the purposes of pedagogical leadership, identifying the key leadership tasks and responsibilities to reach the goals, making decisions about the leadership strategies and scheduling the leadership tasks during the following year. As the plans differed in structure and content, the emphasis of the categories varied between plans. The presence of all categories was limited in some plans.

\section{Discussion of the methodology and reliability}

The ECE centre directors formulated pedagogical leadership plans independently as a part of the project, which means that evaluating the process of the study (Miles et al. 2014:312) mainly includes processing of the data. In qualitative content analysis, prior knowledge or theories about the research subject should not affect the analysis or the findings of the research (Patton 2015:542; Tuomi \& Sarajärvi 2018:108). Moreover, no procedure of the study or researcher influence (Bowen 2009:31) could affect the data content. The pedagogical leadership plans reflect authentically how ECE centre directors perceive and understand pedagogical leadership.

The data were processed and analysed accurately without changing or omitting relevant information, and so the conclusions of the study are consistent with the data. Similarly, the study methodology and design match the research subject, and the findings are credible. The researchers, experts in both education and leadership, 
conducted the analysis in collaboration. In the early stage of the study, all the researchers examined part of the data individually and took notes on the kind of information included in the data. The main analysis was conducted by the two of the researchers as a sequential process, and categorisation of the data was discussed and adjusted during the process.

\section{Findings}

The analysis identified four main categories, which describe how the enactment of pedagogical leadership is conceived by the ECE centre directors. These categories also reflected the sequential phases of action in the leadership planning process taken by the centre directors. Firstly, the fundamental basis of the plans was usually a statement of the goals and the purposes of pedagogical leadership as a basis for sound leadership planning and enactment in the centres. Secondly, the plans contained the descriptions of the key leadership tasks and responsibilities to reach the set goals and purposes. Thirdly, the plans included the directors' decisions about the strategies for enacting the tasks and responsibilities within the centre, and finally, most of the plans scheduled the leadership tasks and the responsibilities during the following year. Figure 1 shows the four main categories, their main contents and their sequential progress.

\section{Setting the goals and the purposes of pedagogical leadership}

The leadership plans stated that pedagogical leadership is to ensure and promote the high quality of pedagogy and the child's overall well-being and learning. The analysis revealed that these goals formulated a fundamental base for further planning of leadership tasks and strategies. Most of the plans presented the goals with the leadership tasks and responsibilities associated with them. It was observed, for example, that developing the expertise of the staff or gathering knowledge about pedagogical practices at an ECE centre were the key leadership tasks associated with the achievement of high-qualitative pedagogy. However, not all of the plans made explicit the goals and the purposes of pedagogical leadership, and those plans mentioning the high quality of ECE did not specify what high pedagogical quality is. Instead, they referred to the Act on Early Childhood Education and Care (540/2018) or the national and local curricula for ECE. The following quotes show examples of the statements about the purposes of pedagogical leadership and the role of the core curriculum in guiding leaders' work in ECE settings:

'The aim of pedagogical leadership is to secure high quality of pedagogy.' (Centre 1)

'The Act on Early Childhood Education and Care and the core curriculum serve as a base for pedagogical leadership.' (Centre 4)

By contrast, some of the plans described, for example, what ensuring a child's well-being means in practice or how to work in a way that respects a child. Another aim generally set was to increase children's and parents' participation in ECE, and in the development of the ECE centre, as well as advocate for the ECE and child's benefit in the community.

\section{Identifying the leadership tasks and responsibilities to reach goals}

In the plans, the enactment of pedagogical leadership comprised the tasks and responsibilities set to reach their goals. Leading pedagogical practices towards the desired pedagogical goals was set as the main task of pedagogical leadership in most of the leadership plans. This included primarily leading curriculum work within the child groups. In the child groups, the educator teams were to compose child group curricula and the pedagogical plans for individual children. In some leadership plans, the development of child group curricula was set as the key target of pedagogical leadership. In one centre, the content areas, for example language, mathematics and arts, of the child group curriculum were described in terms of the development targets in each area. However, the pedagogical leadership plans differed in terms of the accuracy of the specific targets for development of the child group or individual child curricula because some leadership plans only mentioned when the plan was going to be written,

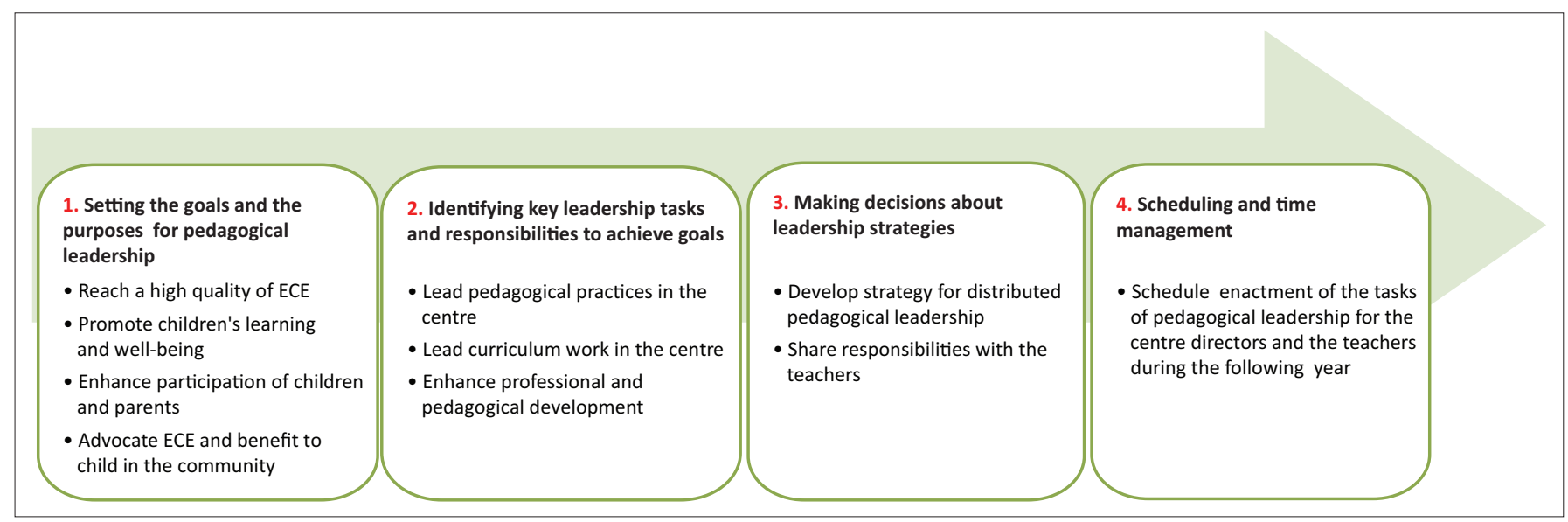

ECE, early childhood education.

FIGURE 1: The contents and sequential progress of the pedagogical leadership action plans. 
finalised and evaluated in the child groups, with no blueprint for leading the development of the contents of the curricula by the centre directors.

Leading assessment and evaluation in the ECE centres and child groups was considered important in pedagogical leadership. Evaluation activities usually included common reflective practices with the staff against the values and goals set in the local curriculum:

'Curriculum assessment and reflection. Are the practices in line with the value base, and how are the developmental targets realised?' (Centre 8)

This quote described the plan for the evaluation of pedagogy and pedagogical development in the whole ECE centre. In addition, evaluation plans usually included the centre directors' observations in the child groups. It was planned to hold the centre directors' observations once or twice a year. Only one centre director mentioned daily visits to child groups. The evaluation plans also included guidelines for the evaluation of child group plans and some mentions of the observations and assessments of daily pedagogy by the staff teams in the child groups. All leadership plans mentioned assessments of the individual children's pedagogical plans. Evaluation plans were usually short lists of the specific evaluation tasks with completion schedules and were only rarely combined with plans for utilisation. Only a few plans described the connection with the development of pedagogy, and in these plans assessment was a requirement for reaching the goals set for pedagogical leadership. One plan stated that the areas for improvement could be identified by assessing the practices.

The involvement of children and parents in the evaluation and development processes were mentioned as the key tasks of pedagogical leadership. In the following quote from a leadership plan, the centre director describes the fundamental principles of evaluation, including the participation of children and parents:

'Common work will be observed and evaluated regularly. The participation of children and parents in the evaluation is important. Also the staff will be encouraged to evaluate their own practices and develop their work.' (Centre 4)

The plans also included decisions about the teachers' responsibilities in completing the leadership tasks. The leadership responsibilities set for teachers included being responsible for curriculum planning and evaluation as well as acting as pedagogical leaders in their own child groups. However, the plans showed wide variety in how the responsibilities were described. Not all of the plans clarified the responsibilities, and sometimes it was difficult to interpret who was meant to be involved in completing the specified tasks. Some parts could be interpreted as implying that the responsibilities were set for the entire centre staff.
According to the statements in the plans, pedagogical leadership included leading the professional development of the staff. However, the plans provided negligible descriptions of the methods that the director intended to use to support the professional development of the educators. There were mentions about assessing educators' skills, identification of the development targets, the provision of guidance and recognition of the needs, desires and strengths of the educators. Sometimes, decisions on improvement were also documented, for example, training programmes. The development targets in the plans were concerned primarily with the pedagogical skills, knowledge and technological skills of the staff. Some of the plans highlighted the importance for professional development of creating a learning community in the ECE centre to encourage the sharing of knowledge and expertise, promote learning for all and enhance reflective practices. The focus in the plans was on the professional development of educators, while only three plans mentioned the importance of developing the director's own professionalism. One of the plans included the director's self-reflection of his leadership skills as well as the plans for improvement. One plan considered it important for the director to have knowledge of both ECE and the quality of pedagogy in their centres, as well as leadership skills.

The leadership tasks described in the plans included also leading the ECE centre's operational culture. This included firstly leading the whole community of the ECE centre, including all ECE stakeholders, children, parents and other professionals who work for or with children, and secondly, leading the structures of the operational culture in the ECE centre. Leading the operational culture of the staff within the centre consisted of creating common working principles as well as increasing the sense of community and positive climate to encourage development and professional interaction. Structures of the operational culture included decisions of the organisation and the practicalities of the development work and the teams, staff compositions within the teams, meeting procedures and the documents to be produced in the teams. Further, cooperative measures with diverse groups, such as meetings with parents, were described.

\section{Deciding the strategies of leadership within the centre}

Distributed leadership approaches were mentioned in the plans as the main strategies to enact the tasks and responsibilities of pedagogical leadership within the ECE centres. In plans where distributed leadership was mentioned, pedagogical leadership was described as an interactive process in which directors not only guide educators, but educators also guide directors, for example by deepening the director's understanding of pedagogical practice. This assumed that everyone in the centre aims to work as well as possible and to constantly develop their practices and professionalism. Trust between the director and educators 
and everyone's commitment to the common goals were stated as being essential. The plans often stated that all educators in an ECE centre were responsible for the quality of ECE and its development.

The distribution of responsibilities was also seen as necessary for the enactment of pedagogical leadership. In connection with the specific tasks of pedagogical leadership, it was usually stated who was responsible for each task and who chaired the meetings. In these plans, ECE teachers were described as being leaders of their staff teams in the child groups. The leadership of the teachers comprised being responsible for the pedagogy, which mainly included the pedagogical activities of the child group, planning and curriculum work as well as guiding pedagogical discussions within the teams. Support from centre directors and colleagues was perceived important:

'In distributed pedagogical leadership, ECE teachers have responsibility for the activities in their child groups. The teachers will receive support from the centre directors, colleagues and the early childhood specialist within the regular structures.' (Centre 7)

There were differences between the centres about how the responsibility of the child group curricula was understood. The responsibility for drawing up the pedagogical plans for individual children was directed at ECE teachers, whereas the creation of the child group curricula was understood as being a responsibility of the staff teams or the teacher alone. However, the responsibility for evaluating and updating the child group curricula was directed at the teams. The whole staff were mentioned as being involved in the evaluation of the pedagogical practices and work culture of the centre.

It was considered important that children and parents also be active participants in improvement work. Their involvement was considered to be significant, especially in the assessment and development processes. Distributed leadership is understood as engaging the whole educational community in leadership, which is perceived as important for commitment:

'Distributed leadership is connected with pedagogical leadership. Early childhood education is created together with the educational community. Everybody has an opportunity to be involved in development of the ECE centre. This principle has been important when bonding people.' (Centre 1)

Although the parents of the children were mentioned as participants in the development work, the plans only rarely mentioned building and maintaining networks in the wider educational communities.

The plans of the centre directors for distributing leadership responsibilities with teachers and teams included descriptions of the leadership structures within the centres. This meant plans for the organisation of group and individual discussions among staff within the centre, decisions about the agreements to be made among staff, descriptions of the assessment, evaluation and development procedures, and schedules for the completion of specific tasks. In some centres, preferred team practices, work communities or colleagues were also defined, as well as the principles for the creation of a good atmosphere in the centre. Moreover, a range of pedagogical documents and assessment materials that guide the work were listed in the plans as tools for leadership and pedagogical development. The plans emphasised the structures, and in one plan, for example, there was a note that the whole document actually dealt with leadership structures.

Three of the plans stated that in addition to the structures for development, pedagogical leadership takes place in everyday encounters with the staff. One plan stated that the improvement of educators' knowledge and skills requires adult pedagogy methods in the ECE centre directors' work.

\section{Time management and scheduling of leadership actions}

The main goals, tasks and responsibilities as well as strategies for enactment were set for the following year in the pedagogical leadership plans. The plans specified the time schedules for the tasks and meetings, pedagogical discussions between the directors and educators, evaluations to be done and their schedules, deadlines for children's individual plans and child group plans and so on. In some plans, these were set in the monthly pies of the annual calendar. In some cases, these pies were linked to a more descriptive written document indicating the goals, tasks and responsibilities as well as strategies for the enactment of pedagogical leadership. However, in some cases, the annual calendar was the only plan made for pedagogical leadership in the centre.

\section{Discussion and implications}

Based on the findings from the analysis of the pedagogical leadership plans, it can be summarised firstly that the focus of pedagogical leadership was on leading pedagogical issues and processes within the ECE centres. Secondly, the main purpose of pedagogical leadership and its diverse tasks was considered as being to develop the ECE centre's pedagogical quality and the children's development and learning. Thirdly, creating structures for pedagogical development and reflection were emphasised in pedagogical leadership, and finally, the plans reflected pedagogical leadership as a distributed leadership approach, as a common task of the work community.

As indicated in previous studies (Corrick \& Reed 2019; Heikka 2014; Heikka \& Waniganayake 2011; Stremmel 2019), this study also revealed how leading the staff's competence is an essential part of pedagogical leadership. The development of the staff's professional competence and development discussions were all emphasised in the plans, as well as leading reflection, which was highlighted as a vital task of pedagogical leadership in the same way as in earlier studies ( $\mathrm{O}^{\prime}$ Sullivan 2009; Stremmel 2019). This required the creation of development structures and, although the pedagogical 
leadership plans emphasised these structures, it was also mentioned that pedagogical leadership was taking place in everyday encounters and discussions with educators. This highlights the need to explore the daily work of ECE stakeholders to find out how pedagogical leadership is enacted in everyday encounters, what the significance of these encounters is and how staff development is being conducted.

According to O'Gorman and Hard (2013), pedagogical leadership focuses on the activities of leading, developing and implementing curricula. In this study, the elements of developing and implementing pedagogy and the ECE curriculum were strongly present, but the actual leading was rarely discussed. The planning focused on the pedagogical goals and tasks of the centre and staff, but the plans relating to leadership enactment were limited. For example, whereas the data included mentions leading professional development and well-being at work, information relating to these tasks was rare and generic, and the plans did not explain explicitly how to systematically promote professional competence and well-being. Another weakness of the plans analysed was that many of them were confined to the schedules of the tasks to be completed, with no significant descriptions of, for example, how to lead the goal-oriented learning of educators. This finding guides ECE centre directors to strengthen the involvement of the educational community in planning of pedagogical leadership in order to find the appropriate and commonly agreed ways of leading professional development of the educators.

Previous studies have indicated (Heikka et al. 2018) that planning is essential for leadership enactment in line with the goals. The FINEEC (2018) also set planned leadership as a quality criterion of ECE in Finland. However, the leaders have no research-based information on how leadership should be planned in ECE in terms of supporting quality in ECE. In this study, this gap can be reflected firstly as a notion of the lack of leadership methods in the plans. Although creating the structures for development and evaluation, leading curriculum work and pedagogical discussions among staff and supporting the educators' professional development were set as the main leadership tasks, the findings failed to answer questions about the specific activities through which the directors aimed to influence. One can conclude that pedagogical leadership plans need to focus more clearly on the actions through which the leader and teachers aim to influence staff and guide the centre staff towards the desired goals. In addition, the plans should also include an evaluation of the effectiveness of these leadership approaches as well as plans for how leaders will develop their own skills.

According to Spillane et al. (2004) and Spillane (2006), leadership artifacts are essential tools for directing leadership, especially when it is distributed between different people and throughout organisational contexts. Pedagogical leadership plans can be understood as artifacts that create interdependence in leadership enactments by the centre directors and the teachers (Heikka 2014; Heikka \&
Suhonen 2019). The plans often stated that leadership would be distributed between the ECE directors and the teachers. The plans varied in how carefully the responsibilities of the centre directors and the teachers, as well as the methods of leading, were described. In distributed pedagogical leadership, centre directors and teachers have separate, but aligned responsibilities (Heikka 2014) that require careful planning. The findings of this study implied that centre directors may miss opportunities for the functional enactment of distributed leadership because of insufficient leadership planning. This finding suggests that more support is needed for the centre directors for planning and implementing distributed forms of leadership appropriately.

The pedagogical leadership plans were drawn up at the ECE centres by the centre directors. Therefore, the documents analysed reflected the perceptions of the centre directors on pedagogical leadership and its enactment within their centres. The plans included few descriptions of how pedagogical leadership was connected with the municipality's strategies or the functions of the educational sector in the municipality. The meaning of pedagogical leadership was rarely discussed in the wider community. This notion is significant as, for example, Heikka and Waniganayake (2011) reported that pedagogical leadership extends beyond the ECE centre level to the wider society or community. One can conclude that the centre directors studied perceived pedagogical leadership as being focused on what happens within their centres and with the teachers. Extending the idea of being a pedagogical leader when cooperating with the sector agents and with stakeholders in the wider municipality could also increase knowledge of the requirements and meaning of high-quality pedagogy within the community, thereby serving as a means to promote early childhood education. It would be important to investigate how pedagogy and pedagogical quality guides the discussions of ECE in the wider municipality cooperation and how the goals and the targets are in line within communities.

The plans examined were made at the beginning of the year, and therefore the findings of the study represent only a certain time in the planning process. To obtain more complete knowledge about the process of planning pedagogical leadership, it should be studied as a long-term process. All in all, the findings of this study can provide relevant information for practitioners, early childhood teacher educators and leadership trainees on how to guide the centre directors in meaningful leadership planning in ECE centres.

\section{Acknowledgements Competing interests}

The authors have declared that no competing interests exist.

\section{Authors' contributions}

All authors contributed equally to the article. 


\section{Ethical considerations}

Ethical clearance was not needed for the study.

\section{Funding information}

This research received no specific grant from any funding agency in the public, commercial or not-for-profit sectors.

\section{Data availability statement}

Data sharing is not applicable to this article as we have no permission for sharing from the studied early childhood centres.

\section{Disclaimer}

The views and opinions expressed in this article are those of the authors and do not necessarily reflect the official policy or position of any affiliated agency of the authors

\section{References}

Act on Early Childhood Education and Care 540/2018 [Varhaiskasvatuslaki 540/2018] viewed30December2019, from https://www.finlex.fi/fi/laki/alkup/2018/20180540.

Atkinson, K. \& Biegun, L., 2017, 'An uncertain tale: Alternative conceptualizations of pedagogical leadership', Journal of Childhood Studies 42(4), 61-68. https://doi. org/10.18357/jcs.v42i4.18104

Bowen, G.A., 2009, 'Document analysis as a qualitative research method', Qualitative Research Journal 9(2), 27-40. https://doi.org/10.3316/QRJ0902027

Corrick, G. \& Reed, M., 2019, 'Pedagogical leadership: Challenges and opportunities', in S. Cheeseman \& R. Walker (eds.), Pedagogies for leading practice, pp. 65-77, Routledge, Oxon.

Ebbeck, M. \& Waniganayake, M., 2004, Early childhood professionals: Leading today and tomorrow, Elsevier, Sydney.

Engel, A., Barnett, W.S., Anders, Y. \& Taguma, M., 2015, Early childhood education and care policy review: Norway, viewed 15 October 2019, from http://www.oecd.org/ norway/Early-Childhood-Education-and-Care-Policy-Review-Norway.pdf.

Finnish Education Evaluation Centre, 2018, Varhaiskasvatuksen laadun arvioinnin perusteet ja suositukset [Guidelines and recommendations for evaluating the quality of early childhood education and care], viewed 15 October 2019, from https://karvi.fi/app/uploads/2018/10/KARVI_vaka_laadun-arvioinnin-perusteetja-suositukset.pdf.

Finnish National Agency for Education (EDUFI), 2018, National core curriculum for early childhood education and care, Finnish National Agency for Education Helsinki.

Fonsén, E., 2008, 'Pedagoginen johtajuus-varhaiskasvatustyön johtamisen punainen lanka [Pedagogical leadership - The thread of leading early childhood education]', unpublished master's thesis, University of Tampere, Tampere.

Fonsén, E., 2014, 'Pedagoginen johtajuus varhaiskasvatuksessa [Pedagogical leadership in early childhood education]', doctoral dissertation, Tampere University Press, Tampere.

Fonsén, E. \& Parrila, S., 2016, 'Johtaja oman työnsä johtajana [Leaders leading themselves]', in S. Parrila \& E. Fonsén (eds.) Varhaiskasvatuksen pedagoginen johtajuus. Käsikirja käytännön työhön, pp. 129-148, PS-Kustannus, Jyväskylä.

Halttunen, L., 2009, 'Päivähoitotyö ja johtajuus hajautetussa organisaatiossa [Day care work and leadership in a distributed organization]', unpublished doctoral dissertation, Jyväskylä University Printing House, Jyväskylä, viewed 15 October 2019, from https://jyx.jyu.fi/dspace/bitstream/handle/123456789/22480/9789513937621.pdf.
Heikka, J., 2014, 'Distributed pedagogical leadership in early childhood education', Acta Universitatis Tamperensis 1908, doctoral dissertation, Tampere University Press, Tampere.

Heikka, J. \& Suhonen, K., 2019, 'Distributed pedagogical leadership functions in early childhood education settings in Finland', South East Asia Early Childhood Journal 8(2), 43-56. https://doi.org/10.37134/saecj.vol8.no2.4.2019

Heikka, J. \& Waniganayake, M., 2011, 'Pedagogical leadership from a distributed perspective within the context of early childhood education', International Journa of Leadership in Education 14(4), 499-512. https://doi.org/10.1080/13603124.20 11.577909

Heikka, J., Halttunen, L. \& Waniganayake, M., 2018, 'Perceptions of early childhood education professionals on teacher leadership in Finland', Early Child Development and Care 188(2), 143-156. https://doi.org/10.1080/03004430.2016.1207066

Heikka, J., Pitkäniemi, H., Kettukangas, T. \& Hyttinen, T., 2019, 'Distributed pedagogical leadership and teacher leadership in early childhood education contexts', International Journal of Leadership in Education. https://www.tandfonline.com/ doi/full/10.1080/13603124.2019.1623923

Heikka, J., Waniganayake, M. \& Hujala, E., 2013, 'Contextualizing distributed leadership within early childhood education: Current understandings, research evidence and future challenges', Educational Management, Administration \& Leadership 41(1), 30-44. https://doi.org/10.1177/1741143212462700

Kagan, S.L. \& Hallmark, L.G., 2001, 'Cultivating leadership in early care and education', Childcare Education Exchange 140, 7-10.

Karila, K., 2001, 'Päiväkodin johtajan muuttuva työ [The changing work of an ECE director]' Lastentarha 64(4), 30-35.

Male, T. \& Palaiologou, I., 2015, 'Pedagogical leadership in the 21st century: Evidence from the field', Educational Management Administration \& Leadership, 43(2), 214-231. https://doi.org/10.1177/1741143213494889

Miles, M.B., Huberman, A.M. \& Saldaña, J., 2014, Qualitative data analysis: A methods sourcebook, 3rd edn., Sage, Los Angeles, CA.

Muijs, D., Aubrey, C., Harris, A. \& Briggs, M., 2004, 'How do they manage? A review of the research on leadership in early childhood', Journal of Early Childhood Research 2(2), 157-169. https://doi.org/10.1177/1476718X04042974

Nivala, V., 1999, 'Päiväkodin johtajuus' [Leadership of educare], doctoral dissertation, Acta Universitatis Lapponiensis 25, University of Lapland, Rovaniemi, Finland.

O'Gorman, L. \& Hard, L., 2013, 'Looking back and looking forward: exploring distributed leadership with Queensland Prep teachers', Australasian Journal of Early Childhood 38(3), 77-85. https://doi.org/10.1177/183693911303800310

O'Sullivan, J., 2009, Leadership skills in the early years: Making a difference, Network Continuum Education, Stafford.

Parrila, S. \& Fonsén, E., 2016, 'Johtajuuden käsitteet ja lähtökohdat' [The concepts and starting points of leadership], in S. Parrila \& E. Fonsén (eds.), Varhaiskasvatuksen pedagoginen johtajuus. Käsikirja käytännön työhön, pp. 23-41, PS-Kustannus, Jyväskylä.

Patton, M.Q., 2015, Qualitative research \& evaluation methods: Integrating theory and practice, 4 th edn., Sage, Thousand Oaks, CA.

Rouse, E. \& Spradbury, G., 2016, 'The role of the educational leader in long day care how do they perceive their role?', Early Child Development and Care 186(3), 1-12. https://doi.org/10.1080/03004430.2015.1036419

Sergiovanni, T.J., 1996, Leadership for the schoolhouse: How is it different? Why is it important? Jossey-Bass, San Francisco, CA.

Soukainen, U., 2013, 'Superior's pedagogical support in distributed organisation of early childhood education', in E. Hujala, M. Waniganayake \& J. Rodd (eds.), Researching Leadership in Early Childhood Education, pp. 127-144, Tampere University Press, Tampere.

Spillane, J.P., Halverson, R. \& Diamond, J.B., 2004, 'Towards a theory of leadership practise: a distributed perspective', Journal of Curruculum Studies 36(1), 3-34.

Stremmel, A.J., 2019. 'Pedagogical leadership as ethical collaborative behavior', in S. Cheeseman \& R. Walker (eds.), Pedagogies for Leading Practice, pp. 78-90, Routledge, Oxon.

Tuomi, J. \& Sarajärvi, A., 2018, Laadullinen tutkimus ja sisällönanalyysi, Uudistettu laitos [Qualitative research and content analysis, Revised edition], Kustannusosakeyhtiö Tammi, Helsinki.

Waniganayake, M., Cheeseman, S., Fenech, M., Hadley, F. \& Shepherd, W., 2017, Leadership: Contexts and complexities in early childhood education, 2 nd edn Oxford University Press, South Melbourne. 